\title{
Failure Theories and Notch Type Effects on the Mechanical Properties of Jute-Glass Hybrid Composite Laminates
}

\author{
Raphael Siqueira Fontes ${ }^{a, c}\left(\right.$, Hallyjus Alves Dias Bezerra ${ }^{a}$, Ana Claudia Melo de Caldas Batista ${ }^{a}$, \\ Sérgio Renan Lopes Tino $\hat{o}^{a, b} \mathbb{D}^{\mathbb{D}}$, Eve Maria Freire de Aquino ${ }^{a} \mathbb{C}$ \\ a Programa de Pós-Graduação em Engenharia Mecânica, Centro de Tecnologia, Universidade Federal \\ do Rio Grande do Norte (UFRN), Campus Universitário, CEP: 59072-970, Lagoa Nova, Natal, RN, \\ Brasil \\ ${ }^{b}$ Instituto Federal de Educação, Ciência e Tecnologia de Goiás (IFG), Luziânia, GO, Brasil \\ 'Instituto Federal de Educação, Ciência e Tecnologia do Rio Grande do Norte (IFRN), Mossoró, RN, \\ Brasil
}

Received: April 12, 2018; Revised: November 30, 2018; Accepted: January 07, 2019

This study aimed to analyze the mechanical properties and damage characteristics in uniaxial tensile loading of two hybrid composite laminates consisting of an ortho-therephthalic polyester matrix reinforced by bidirectional jute fabrics and E-glass fibers, with different configurations and types of geometric discontinuities in the longitudinal section, characterized by the presence of a circular hole and semicircular notches. A semi-empirical study was conducted using the residual properties obtained in mechanical tests, as well as the Point Stress Criterion (PSC) and Average Stress Criterion (ASC) failure theories. This study is based on the calculation of distances $\left(d_{0}\right.$ and $\left.a_{0}\right)$ in the neighborhood of both the hole and the notches, the area of failure stress. The results show the direct influence of geometric discontinuity and residual and modulus strengths in all the parameters studied. With respect to failure theories, only the PSC showed good agreement when the K equal to 2.36 or 2.58 values was used.

Keywords: Composites, fracture, mechanical properties, geometric discontinuity.

\section{Introduction}

An increasingly important area in the field of engineering is the development of new materials aimed at meeting a host of conditions, combining high-performance structural properties (lightness, easy handling and high mechanical response) with low production and operational costs ${ }^{1-3}$. Currently natural fibers such as jute fiber composite materials are replacing the sinthetic fibers owing to their easy availability and cost. The use of natural fibers is improved remarkably due to the fact that the field of application is improved day by day especially in automotive industries. Several researches have been taken place in this direction ${ }^{4,5}$.

Jute is an important natural fibre occupying second place in the economic market after the cotton and mainly utilized for industrial application. India, Bangladesh, China, Nepal and Thailand are the major producers of jute accounting for over $95 \%$ of the global output. Good mechanical properties of jute fibres when compared with other natural fibre, such as sisal, coir, and ramie are intended to make reinforced composites. The nonabrasive nature of jute, which permits higher fibre loading and low rate of damage to the mould is compared with the glass fibre composite quality ${ }^{5}$.

Given this development, an increasingly viable possibility for the different applications has been found in polymer composite materials. Within this class, hybrid composite materials stand out, especially in the case of possible

*e-mail: sergiorlt@yahoo.com.br environmental damage, where these materials have blended synthetic and natural fibers ${ }^{6-10}$. Composite materials, mainly natural and/or synthetic fiber-reinforced plastics, have played an important role in these studies, since they meet the aforementioned requirements, in addition to their low weight and low cost, essential parameters in many structural applications $^{2,6}$.

One of the most frequent design conditions in structural elements is the presence of geometric discontinuities, such as holes and notches. The influence of these types of discontinuities in preventing the failure of these structural elements, whether in determining their ultimate tensile strength and/or fracture characteristics, is a determining factor ${ }^{11}$.

Thus, several studies have been conducted involving experimental and numerical analysis in order to quantify stress concentration in composites through failure theories such as the Point Stress Criterion (PSC) and Average Stress Criterion (ASC) $)^{12-14}$. Since these analyses are primarily carried out in composite materials reinforced only with synthetic fibers, it is important to apply models to composites reinforced with natural fibers such as jute, which are widely used in laminate composite structures.

This paper is distinctively 'innovative' because aims to conduct an in-depth investigation into the use of jute/glass hybrid composite laminates and the influence of different parameters associated with stress concentration on the mechanical properties and damage mechanisms involved, that until today, is focus to researchers in composites. 
In this respect, the present study assesses the mechanical response (strength and young's modulus), macroscopic fracture characteristics, and residual properties (modulus and strength) of two hybrid composite laminates with a polymer matrix and geometric discontinuities in their longitudinal section, under the action of uniaxial tensile testing. These geometric discontinuities are characterized by a $6 \mathrm{~mm}$ circular hole and $3 \mathrm{~mm}$ semicircular lateral notches (highlights that both have radius of $3 \mathrm{~mm}$ ).

Hybrid composite laminates are composed of an orthoterephthalic polyester matrix reinforced with four layers of bidirectional jute fiber and one central layer of E-glass fiber fabric, with a different fiber direction in the outer layers.

These configurations were developed for application in femoral prostheses, where E-glass fiber comes in the fact of having low cost and high potential of structural application, however the jute fiber, due it is not harmful to the environment. The RoHM (rule of hybrid mixtures) in not used because the transverse and shear properties (used to prostheses) due the spatial variation of microstresses inside the representative element volume is not effective ${ }^{15}$.

The laminate configurations aim to study the influence not only of their residual and mechanical properties, but also the anisotteropic behavior in the kind of geometric discontinuity (hole and lateral notch), due to the two different configurations on the outer layer of the composites.

In this study, stress concentration was investigated considering that changes in laminate strength are based on the experimental calculation of Residual Strength $(R S)$ and Residual Modulus $(R M)$, using the concepts determined by ASTM standard D 5766 ${ }^{16}$. Residual Strength was also used in the Point Stress Criterion (PSC) and Average Stress Criterion (ASC) failure theories for the semi-empirical calculation of distances $\left(d_{0}\right.$ and $\left.a_{0}\right)$ around the hole and lateral notch, the area of failure stress ${ }^{12-14}$.

Finally, macroscopic and microscopic analyses of final fracture characteristics were performed to understand the effects of the hole and lateral notch on the final fracture.

\section{Materials and Methods}

\subsection{Laminate Configuration}

The laminate is industrially manufactured and the matrix and fibers were provided by "Tecniplas Nordeste Indústria e Comércio Ltda". The laminate was obtained using the hand lay-up process. The polyester resin is of industrial use because it has good impregnation and mechanical properties when used in polymeric composites ${ }^{1}$. The raw material used as matrix was ortho-terephthalic polyester resin (NOVAPOL L-120) and as reinforcement flat bidirectional E-glass fiber fabric (GFF) $\left(600 \mathrm{~g} / \mathrm{m}^{2}\right)$, and bidirectional jute fiber fabric (JFF) $\left(306 \mathrm{~g} / \mathrm{m}^{2}\right)$. The laminates were manufactured using different configurations (Fig. 1). Fiber direction is related to the direction of the applied load. The first configuration is defined as $\left[\mathbf{J F F}\left( \pm \mathbf{4 5}^{\circ}\right) / \mathbf{J F F}\left(\mathbf{0} / \mathbf{9 0}^{\circ}\right) / \mathbf{G F F}\left(\mathbf{0} / \mathbf{9 0}{ }^{\circ}\right) / \mathbf{J F F}\left(\mathbf{0} / \mathbf{9 0}^{\circ}\right) /\right.$ $\operatorname{JFF}\left( \pm \mathbf{4 5}^{\circ}\right)$ ] (Figure 1(a)), and denominated L1. The second is defined as $\left.\left[\mathbf{J F F}\left(\mathbf{0} / \mathbf{9 0}^{\circ}\right)_{2} / \mathbf{G F F}\left(\mathbf{0} / \mathbf{9 0} 0^{\circ}\right) / \mathbf{J F F}(\mathbf{0} / \mathbf{9 0})_{2}\right)_{2}\right]$ (Figure 1(b)) and denominated $\mathbf{L 2}$. It should be noted that in Figure 1 the transparent layers representing the matrix are only illustrative, i.e. do not separate during the manufacturing process, since they are impregnated directly in the reinforcing layers of the laminate. It is important to remember that both configurations were manufactured using bidirectional fabrics with the same fiber bundle ratio in the weft and warp.

\subsection{Specimens cutting and preparation}

The dimensions of the unnotched specimens (L1U and L2U) were determined using ASTM D $3039{ }^{17}$ standard, while for test specimens with a $6 \mathrm{~mm}$ central hole $(\mathbf{L 1 H}$ and L2H), ASTM D 5766 standard. was applied ${ }^{16}$. This standard was adapted to manufacture the test specimens with $3 \mathrm{~mm}$ semicircular lateral notches (L1N and L2N). The same dimensions as those employed for the hole (hole diameter is the same notch diameter) were used for these test specimens. The drills used to make the holes and the milling cutters to obtain the notches had diamond threads, to avoid possible irregularities on the surfaces of the discontinuities. Postdrilling delaminations and microcracks were not observed in macroscopic analyse. Table 1 shows the main characteristics and dimensions of the test specimens. All test specimen dimensions were within the standard tolerance of $\pm 1 \%$.

\subsection{Density testing}

The volumetric density of the composites was determined using ASTM D $792^{18}$. The samples were weighed on a digital balance with a maximum capacity of $210 \mathrm{~g}$ and resolution of $0.1 \mathrm{mg}$.

\subsection{Tensile Test}

Uniaxial tensile testing was conducted to determine tensile strength and longitudinal young's modulus (in the direction of the applied load) of the composite laminates. Therefore, eight specimens for each condition were confectioned, obtaining five tests considered as valid according to the technical standard. Displacement velocity in uniaxial tensile testing was $1.0 \mathrm{~mm} / \mathrm{min}$ (standard) for all test specimens. All tests were carried out at ambient temperature using a mechanical universal testing machine (Shimadzu AGI-250 $\mathrm{KN}$ ) with maximum capacity of $25 \mathrm{~T}$.

Highlighting is done for calculation of the Young's modulus it is determined considering the stress and strain values up to about $50 \%$ of the breaking load, in order to avoid influence of damage on it. This procedure was adopted to calculate Young's modulus of all the specimens.

The influence of losses in tensile strength and Young's modulus in the composite laminates, due to geometric discontinuity, will be studied using Residual Strength $(R S)$ 


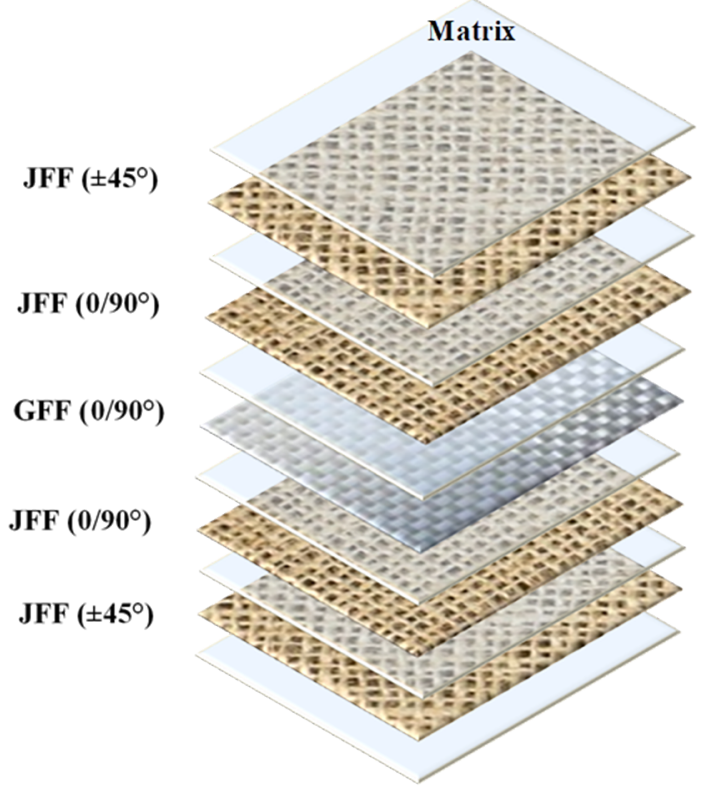

(a)

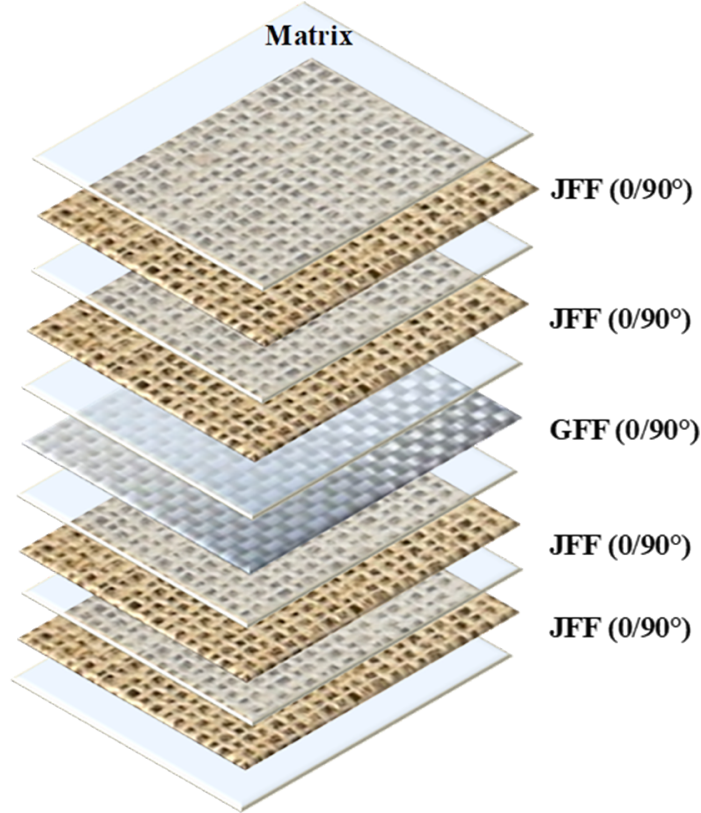

(b)

Figura 1. Configurations of Hybrid Composite Laminates: (a) L1; (b) L2.

Table 1. Characteristics and dimensions of test specimens.

\begin{tabular}{cccccc}
\hline $\begin{array}{c}\text { Laminate } \\
\text { Configuration }\end{array}$ & Specimen Name & Definition & Specimen Length & Specimen Width & Specimen Gage \\
\hline \multirow{2}{*}{ L1 } & L1U & Unnotched & $250 \mathrm{~mm}$ & $25 \mathrm{~mm}$ & \\
& L1H & Hole diameter $=6.0 \mathrm{~mm}$ & $200 \mathrm{~mm}$ & $36 \mathrm{~mm}$ & \\
& L1N & Notch radius $=3.0 \mathrm{~mm}$ & $250 \mathrm{~mm}$ & $36 \mathrm{~mm}$ & \multirow{2}{*}{$127 \mathrm{~mm}$} \\
\multirow{2}{*}{ L2 } & L2U & Unnotched & $250 \mathrm{~mm}$ & $25 \mathrm{~mm}$ & \\
& L2H & Hole diameter $=6.0 \mathrm{~mm}$ & $250 \mathrm{~mm}$ & $36 \mathrm{~mm}$ & \\
& L2N & Notch radius $=3.0 \mathrm{~mm}$ & $250 \mathrm{~mm}$ & $36 \mathrm{~mm}$ & \\
\hline
\end{tabular}

and Residual Modulus $(R M)$ of the composite laminates $16,19,20$, which are defined as:

$$
\begin{gathered}
R S=\frac{\sigma_{\text {Notched }}}{\sigma_{\text {Unnotched }}} \\
R M=\frac{E_{\text {Notched }}}{E_{\text {Unnotched }}}
\end{gathered}
$$

where $\sigma_{\text {Notched }}$ is defined as the ultimate tensile strength of test specimens with geometric discontinuity (calculated in the largest cross-sectional area, according to ASTM D $5766{ }^{15}$ standard); $\sigma_{\text {Unnotched }}$ is the ultimate tensile strength of test specimens with no geometric discontinuity (calculated in the largest cross-sectional area, according to ASTM D $3039^{17}$ standard); $E_{\text {Notched }}$ and $E_{\text {Unnotched }}$ correspond to the longitudinal Young's modulus of test specimens with and without geometric discontinuity, respectively.

The characteristic distances $\left(a_{0}\right.$ and $\left.d_{0}\right)$ were calculated according to the Point Stress Criterion (PSC) and Average
Stress Criterion (ASC) failure theories; these will be discussed in greater detail in the results.

\subsection{Fracture analysis in mechanical testing}

The fracture region was macroscopically analyzed to study the final fracture characteristic (previously fractured test specimens). Macroscopic analysis of the fracture involved scanner verification of the fracture process along the entire length of the test specimen. Microscopic analysis was performed by SEM like a comparative study of final fracture.

\section{Results and discussion}

\subsection{Volumetric density}

The average value of the volumetric densities for the composite laminates are: $\mathbf{L 1}\left(1.25 \mathrm{~g} / \mathrm{cm}^{3}\right)$ and $\mathbf{L} \mathbf{2}\left(1.26 \mathrm{~g} / \mathrm{cm}^{3}\right)$. It can be seen that both composite laminates have low densities, which is excellent for applications in lightweight 
structures. It is also emphasized that the two laminates can be considered having the same volumetric density, not having any influence of volumetric density on the results obtained with respect to the final response of the material.

\subsection{Tensile Tests - Unnotched Specimens}

The influence of anisotropy is related to the mechanical response of composite laminates $\mathbf{L} 1$ and $\mathbf{L} 2$ in the uniaxial tensile test of the unnotched test specimens (L1U and L2U). Figure 2 shows the stress $x$ strain behavior for the two configurations obtained by the mean of the valid test curves, for at least five specimens, according to the technical standard ${ }^{16}$. The average values obtained for tensile strength and Young's modulus (in the direction of the applied load) are presented in Table 2, as well as their respective standard deviations. Young's modulus of the all composite laminates were determined using the stress and strain values before damage, in order to prevent their possible influence on the results.

Hybrid composite laminates containing natural fibers exhibit standard deviations within an acceptable margin ${ }^{21}$. It is important to highlight that the presence of fibers with different mechanical and physical properties in a composite laminate may cause high dispersions when compared to laminates reinforced with a single fiber type, primarily in the case of synthetic fibers ${ }^{1,22}$. All dispersions on this paper are characterized by the absolute difference between the maximum and minimum values found in the tests.

The results show that placing fibers at $\pm 45^{\circ}$ to the direction of the applied load in the outer layer of laminate $\mathbf{L 1}$, when compared to laminate $\mathbf{L 2}$, resulted in an increase in both strength $(30.80 \%)$ and Young's modulus, $(7.33 \%)$.

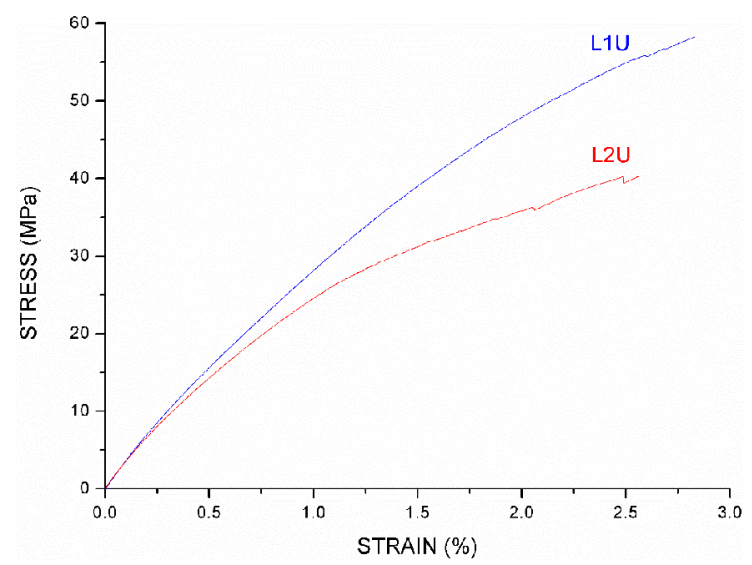

Figure 2. Stress x strain diagram - Unnotched test specimens.

Table 2. Mechanical properties - Unnotched test specimens.

\begin{tabular}{ccc}
\hline SPECIMEN & $\begin{array}{c}\text { Tensile Strength } \\
\mathbf{( M P a )}\end{array}$ & $\begin{array}{c}\text { Young's Modulus } \\
\mathbf{( G P a )}\end{array}$ \\
\hline L1U & $58.25 \pm 1.09$ & $3.00 \pm 0.12$ \\
L2U & $40.31 \pm 2.69$ & $2.78 \pm 0.16$ \\
\hline
\end{tabular}

The outer layers with fibers at $0 / 90^{\circ}$ produced a lower load at the onset, influencing the final tensile result of the laminate.

Lautenschläger et al. ${ }^{23}$ focused on the influence of two fillers with different particle shape on the tensile and flexural properties of SMC and BMC; thus they concluded that the tensile mechanical properties of the jute nonwoven reinforced SMC material are quite high compared to the values of jute reinforced composite found in literature and that there was also anisotropy influence on the tensile final mechanical behavior (50 MPa for nonwoven $\mathrm{SMC} \mathrm{C} 0^{\circ}$ and $81 \mathrm{MPa}$ for nonwoven $\mathrm{SMC} \mathrm{C} 90^{\circ}$ ).

With respect to fracture characteristics, although test specimens $\mathbf{L 1 U}$ and $\mathbf{L} \mathbf{U}$ showed no saturation in matrix fissuring, fissures transverse to the applied load are concentrated in the region of the final fracture. Fiber pull-out (nonadherence of the fiber/matrix interface) was observed in the central layer (bidirectional glass fiber tissue), as shown in Figure 3. In macroscopic analysis of the damage sustained, LGM (Lateral Gage Middle) was the type of final fracture, according to ASTM D $3039{ }^{17}$ standard, for

\subsection{Tensile Tests - Open Hole Specimens}

The influence of a central hole on the mechanical properties of composite laminates (specimens $\mathbf{L 1 H}$ and $\mathbf{L 2 H}$ ) is shown in Figure 4, using profiles shown on a stress x strain diagram, obtained by the mean of the valid test curves, for at least 5 specimens, according to the technical standard ${ }^{16}$. Table 3 shows the average values obtained for tensile strength and Young's modulus (in the diection of the applied load), as well as their respective standard deviations.

As observed for the condition without discontinuities, the standard deviations exhibited are within an acceptable margin, given that, in addition to the presence of different types of reinforcements, discontinuity induces a greater variation in the results obtained, thereby increasing result dispersion ${ }^{18}$. In the case of test specimens with no geometric discontinuity, L1H shows an increase in strength (35.97\%). On the other hand, in relation to young's modulus, test specimens L1H exhibited a decline of $26.77 \%$, when compared to test specimens $\mathbf{L 2 H}$, demonstrating that a central hole affects laminate $\mathbf{L} 1$ more than laminate $\mathbf{L} 2$.

With respect to macroscopic analysis of the fracture (Figure 5), there were no significant differences in test specimens with a hole $(\mathbf{L 1 H}, \mathbf{L 2 H})$ compared to test specimens $\mathbf{L 1 U}$ and $\mathbf{L} \mathbf{2} \mathbf{U}$. In other words, the final fracture was localized, with fiber pull-out and LGM ${ }^{17}$.

\subsection{Tensile Tests - Lateral Notched Specimens}

As with test specimens with a hole, Figure 6 shows the profiles of stress $x$ strain behavior obtained by the mean of the valid test curves, for at least 5 specimens, according to the technical standard ${ }^{16}$. Table 4 shows the average values obtained for tensile strength and young's modulus (in the 


\section{Direction of loading}

(a)

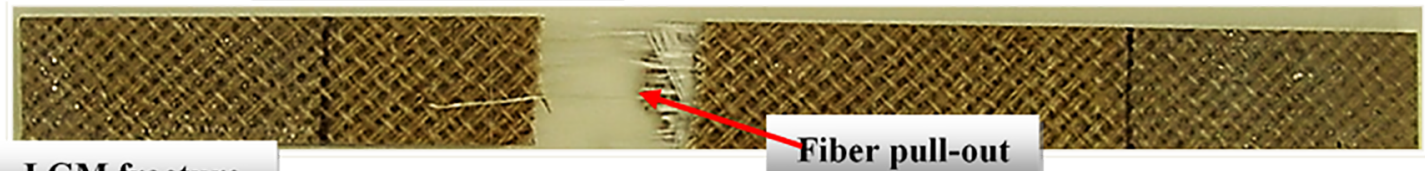

LGM fracture

(b)

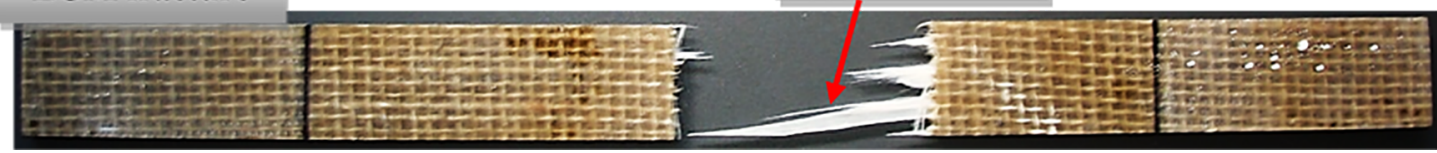

Figure 3. Characteristic of final fracture in tensile testing for: (a) $\mathbf{L 1 U}$, (b) $\mathbf{L} 2 \mathbf{U}$.

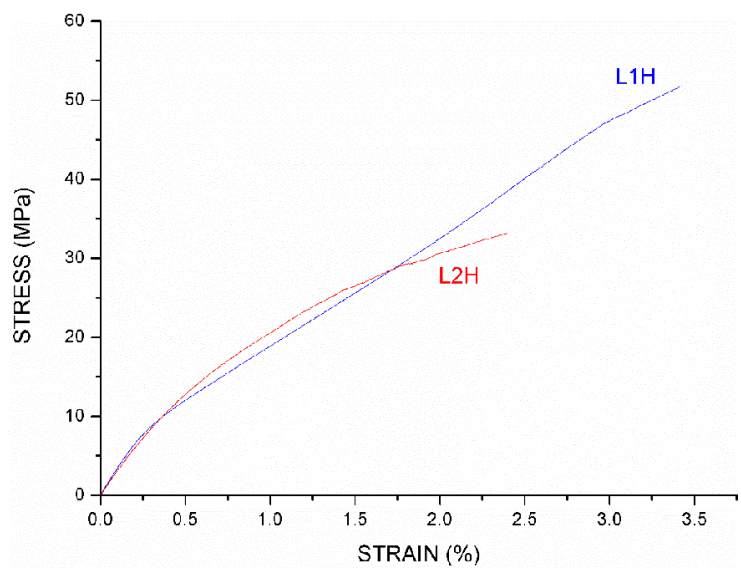

Figure 4. Stress $x$ strain diagram - Test specimen with central hole.

Table 3. Mechanical properties - Test specimens with central hole.

\begin{tabular}{ccc}
\hline SPECIMEN & $\begin{array}{c}\text { Tensile Strength } \\
\text { (MPa) }\end{array}$ & $\begin{array}{c}\text { Young's Modulus } \\
\text { (GPa) }\end{array}$ \\
\hline L1H & $51.82 \pm 3.12$ & $1.86 \pm 0.24$ \\
L2H & $33.18 \pm 2.98$ & $2.54 \pm 0.24$ \\
\hline
\end{tabular}

direction of applied load), as well as their respective standard deviations.

In contrast to that exhibited by other test specimens, the influence of semicircular lateral notches on young's modulus $(0.39 \%)$ was within the margin of dispersion. However, this influence is greater on the strength (44.54\%) of L1N test specimens when compared to the $\mathbf{L} \mathbf{2 N}$ laminate.

Macroscopic analysis of the fracture showed no differences between unnotched test specimens with a hole and with a notch, given that the LGM fracture ${ }^{16}$ demonstrated fiber pull-out (Figure 7).

\subsection{Comparative Studies - Geometric Discontinuities/Laminates $\mathbf{L 1}$ and $\mathbf{L 2}$.}

The stress versus strain diagram for composite laminate $\mathbf{L 1}$ (Figure 8) shows that the presence of geometric discontinuities has no influence on the initial profile of mechanical response (obtained by the mean of the valid test curves). With respect to laminate $\mathbf{L} 1$ test specimens, that is, L1U, L1H and L1N, there is linearity between stress and strain up to a certain load, namely, the initial damage load, in each condition studied. Another factor that can influence this behavior is the presence of shearing, added to traction, due to the direction of outer layer fibers in relation to the direction of the load. It is important to underscore that this behavior is typical of an orthotropic composite with reinforcement at $45^{\circ}$ to the applied load ${ }^{21}$.

However, in relation to losses and/or gains in mechanical properties, young's modulus in the region before the onset of damage (identified by the change in the slope of the graph), is noteworthy; that is, the greatest influence was for specimens with a central hole $(\mathbf{L 1 H})$.

This same behavior profile can be observed for the stress versus strain diagram in laminate L2 (Figure 9, obtained by the mean of the valid test curves). Geometric discontinuity, whether a hole or lateral notches, exhibited little influence on the young's modulus of the laminate, when compared to tensile strength.

The little influence of Young's modulus (except L1H) results in the calculation of distances $\mathrm{a}_{0}$ and $\mathrm{d}_{0}$, whereby, according to failure theories PSC and ASC, the concentration factors of stress $\mathrm{K}$ can be considered factors dependent only on geometry.

A hybrid bio-composite in the form of pultruded layers manufactured with jute bio-fibers, combined with unidirectional roving E-glass, and embedded in a polymeric matrix was chosen for Shane Johnson et al. ${ }^{24}$, without which stress strain curves are generated for these dually reinforced systems in transverse, axial and shear modes to calibrate the nonlinear parameters for computational models. The results show that all of the models match the full-field TSA and DIC results under a multi-axial state of stress; however, the Anisotropic Potential Theory (APT) model showed more response at stress concentrations than the Anisotropic Deformation Theory (ADT) model. Thus, the bio-composite reinforced by jute presents good application with respect to possible structural applications.

\subsection{Experimental Residual Properties}

Residual Strength $\left(R S_{E X P}\right)$ and Residual Modulus $\left(R M_{E X P}\right)$, according to ${ }^{16,19,20}$, were calculated from Equations (1) and (2) for all configurations (Figures 10 and 11). 
(a)

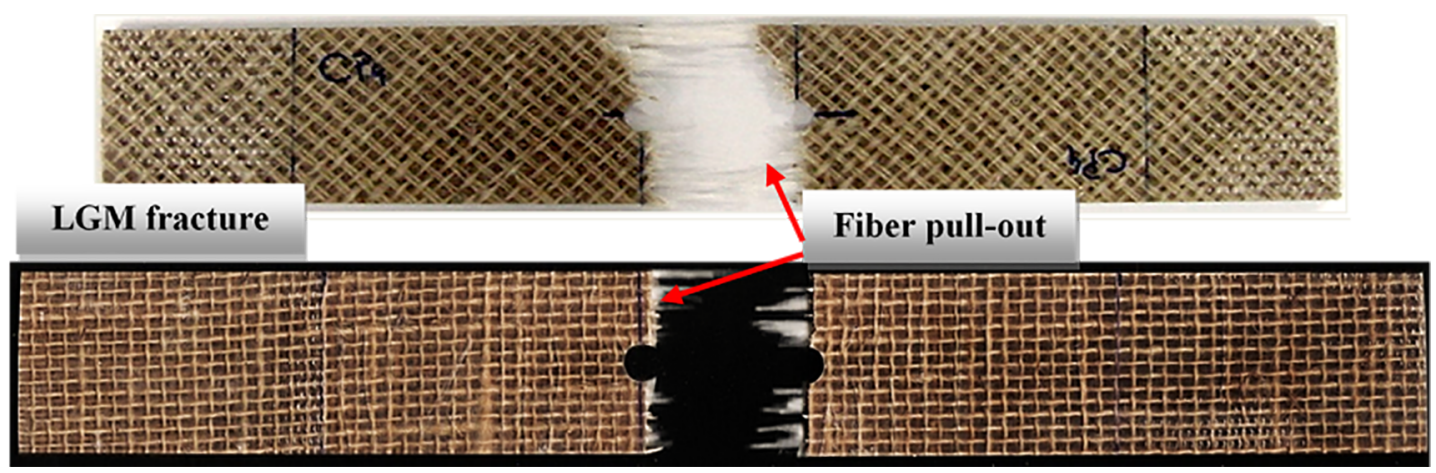

Figure 5. Characteristic of the final fracture in tensile testing for (a) $\mathbf{L 1 H}$, (b) $\mathbf{L 2 H}$.

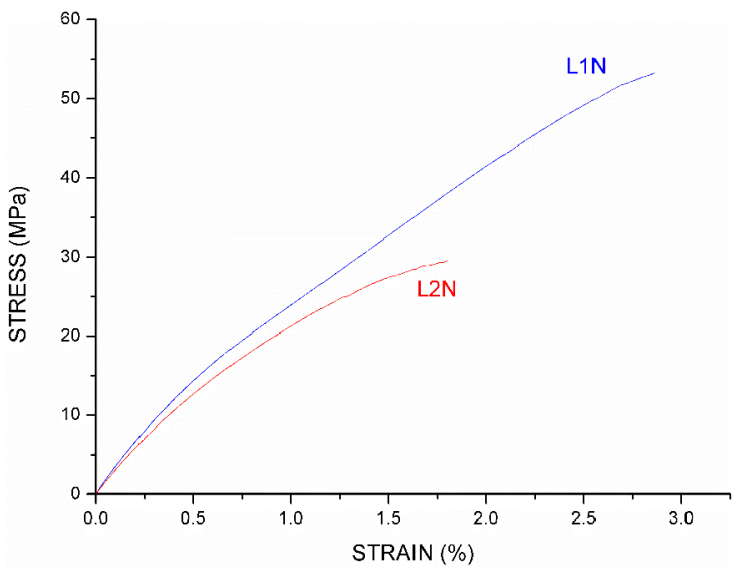

Figure 6. Stress $x$ strain diagram - Test specimens with a lateral notches.

Table 4. Mechanical properties - Test specimens with lateral notches.

\begin{tabular}{ccc}
\hline SPECIMEN & $\begin{array}{c}\text { Tensile Strength } \\
(\mathbf{M P a})\end{array}$ & $\begin{array}{c}\text { Young's Modulus } \\
(\mathbf{G P a})\end{array}$ \\
\hline L1N & $53.25 \pm 1.82$ & $2.58 \pm 0.12$ \\
L2N & $29.53 \pm 1.84$ & $2.57 \pm 0.13$ \\
\hline
\end{tabular}

Analysis of residual properties (tensile strength) shows that laminates L1 and L2 (influence of the configuration) exhibit different behaviors in relation to the type of geometric discontinuity. In the case of laminate L1, a greater influence of the central hole $(11.04 \%$, versus $8.58 \%$, for semicircular notches) was observed. It is important to highlight that this difference is within the margin of test dispersion (Figure 10). In laminate L2, however, the greater loss was found for semicircular notches $(26.74 \%$, versus $17.69 \%$ for the central hole).

Analysis of Young's modulus showed greater sensitivity to discontinuity in laminate $\mathbf{L} 1$, regardless of the type of discontinuity. On the other hand, considering the margins of dispersion of the tests, $\mathbf{L 2}$ exhibited no influence of discontinuity (both central hole and semicircular notches) on Young's modulus.

\subsection{PSC and ASC Failure Theories}

Over the years, a number of criteria have attempted to predict the Residual Strength of composites in the presence of a circular hole, highlighting the Point-Stress Criterion (PSC) and Average-Stress Criterion (ASC) failure theories. However, for semicircular notches, these theories have yet to be frequently applied. Thus, an extended analysis of this type of geometric discontinuity is needed to compare behaviors in terms of the effect of stress concentration.

The PSC assumes that failure will occur when stress $\left(\sigma_{N}\right)$ at a certain small fixed distance $d_{0}$ ahead of the hole boundary first reaches tensile strength $\sigma_{f}$ of the material (or the tensile strength of the plate without a hole, $\left.\sigma_{U N}\right)^{25,26}$. According to Whitney and Nuismer ${ }^{27}$ this residual strength can be expressed by:

$$
R S_{P S C}=\frac{\sigma_{N}}{\sigma_{U N}}=\frac{2}{2+\xi_{1}^{2}+3 \xi_{1}^{4}-(K-3)\left(5 \xi_{1}^{6}-7 \xi_{1}^{8}\right)}
$$

Where:

$$
\xi_{1}=R /\left(R+d_{0}\right)
$$

Where $R$ is defined as the hole radius and $K$ the stress concentration factor.

The ASC assumes that the failure will occur when the average value of the stress $\left(\sigma_{N}\right)$ over some small fixed distance $a_{0}$ ahead of the hole boundary first reaches the tensile strength $\sigma_{f}$ of the material (or the tensile strength of the plate without a hole, $\left.\sigma_{U N}\right)^{25,26}$. According to Whitney and Nuismer ${ }^{27}$ this residual strength can be expressed by:

$$
R S_{A S C}=\frac{\sigma_{N}}{\sigma_{U N}}=\frac{2\left(1-\xi_{2}\right)}{2-\xi_{2}^{2}-\xi_{2}^{4}+(K-3)\left(\xi_{2}^{6}-\xi_{2}^{8}\right)}
$$

Where:

$$
\xi_{2}=R /\left(R+a_{0}\right)
$$




\section{(a)}

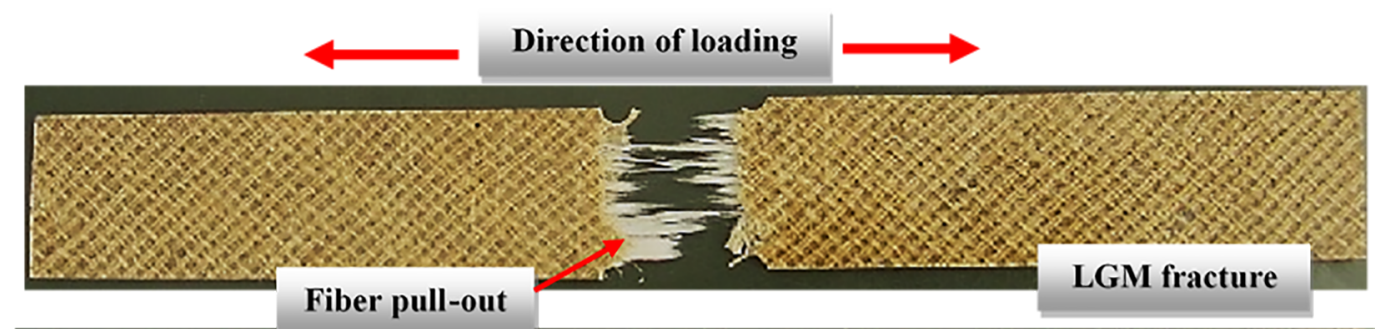

(b)

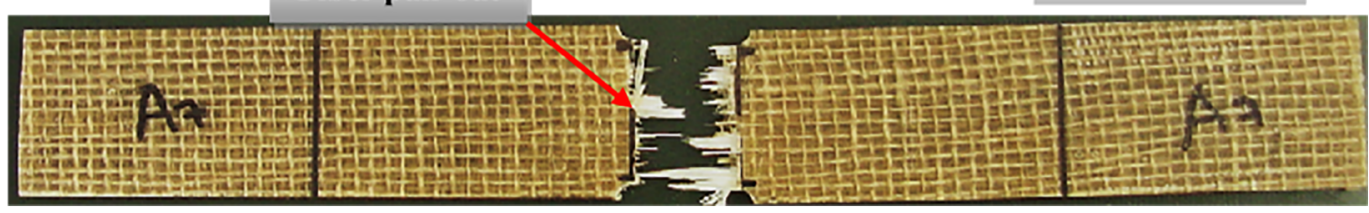

Figure 7. Characteristics of the final fracture in tensile testing for (a) $\mathbf{L 1 N}$, (b) $\mathbf{L} 2 \mathbf{N}$.

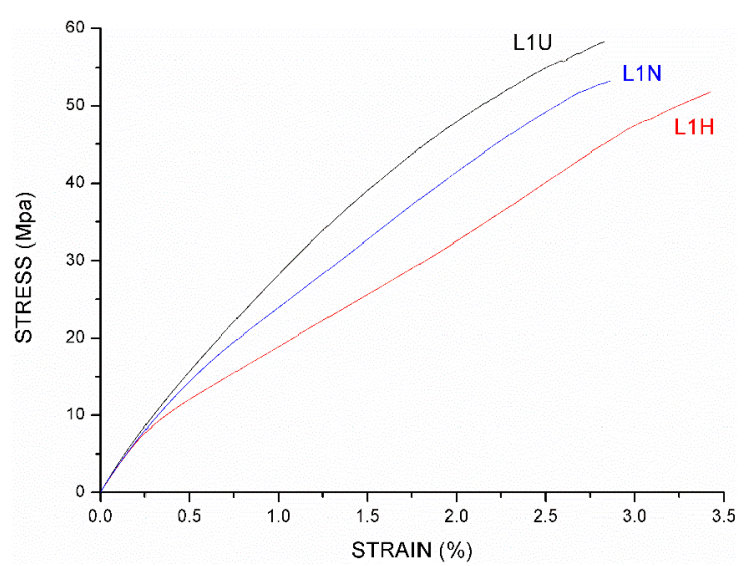

Figure 8. Stress x strain graph - Laminate L1.

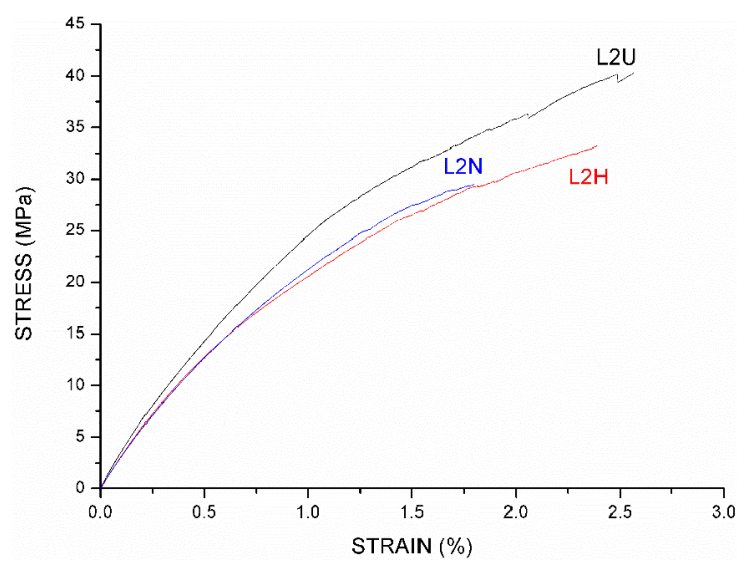

Figure 9. Stress x strain graph - Laminate L2.

Where $R$ is also defined as the hole radius and $K$ the stress concentration factor.

It is worth noting that for isotropic or quasi-isotropic materials, the value of $K$ is assumed to be 3.0 in both criteria. The values of characteristic distances $d_{0}$ and $a_{0}$ are generally determined by the averages of the experimental data curves obtained through the tensile test of several specimens with different hole sizes, and in some literature data, ${ }^{24} d_{0}$ equals $1.0 \mathrm{~mm}$ and $a_{0} 3.75 \mathrm{~mm}$. The models also assume that the

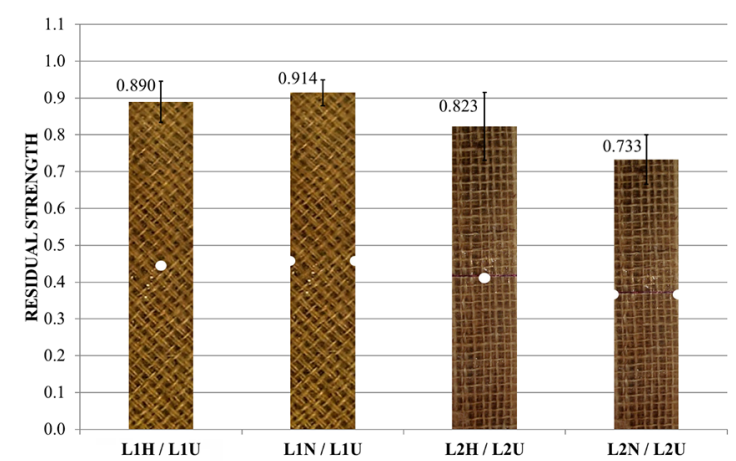

Figure 10. Residual strength - Composite laminates L1 and L2.

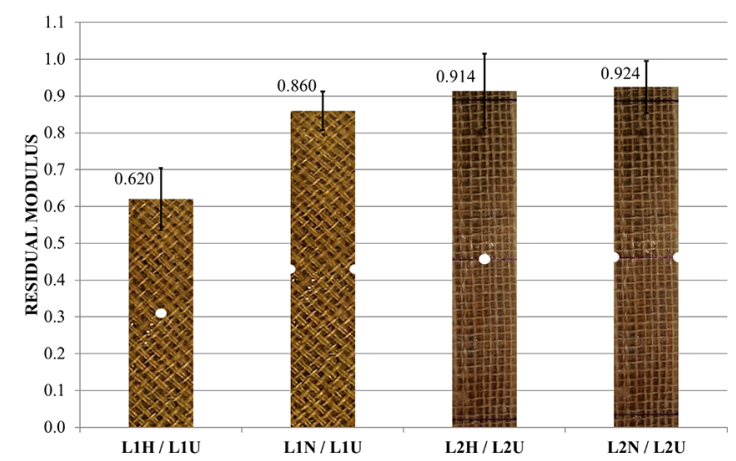

Figure 11. Residual moduli - Composite laminates L1 and L2.

values of distances $d_{0}$ and $a_{0}$ depend on the fiber/matrix system and laminate configuration.

Thus, the purpose is to determine these distances semiempirically, that is, considering the PSC and ASC failure models and the $R S$ values for both $\mathbf{L} \mathbf{1}$ and $\mathbf{L} \mathbf{2}$ configurations (with hole and lateral notches). For the semi-empirical calculation of $d_{0}$ and $a_{0}, K=2.58$ was used for hole specimens and 2.36 for notched specimens, determined solely in relation to the geometry of the specimen, ${ }^{11,19}$ since $K=3.0$ could not be used because both configurations were orthotropic.

Considering the stress concentration factor only as a function of geometry is also based on the behaviors exhibited by laminates $\mathbf{L} \mathbf{1}$ and $\mathbf{L 2}$, in terms of Young's modulus, that is, 
Table 5. Values of $d_{0}$ and $a_{0}$ with the respective percentages of $\eta$.

\begin{tabular}{cccccc}
\hline Configuration & $\begin{array}{c}\text { Stress Concentration } \\
\text { Factor } K\end{array}$ & PSCd $(\mathbf{m m})$ & $\boldsymbol{\eta}(\boldsymbol{\%})$ & ASCa $_{0}(\mathbf{m m})$ & $\boldsymbol{\eta}(\%)$ \\
\hline L1H & 2.58 & 3.7 & 24.7 & 17.0 & 113.0 \\
L1N & 2.36 & 5.0 & 33.3 & 20.0 & 133.0 \\
*L2H & 2.58 & 2.9 & 19.7 & 11.5 & 76.7 \\
L2N & 2.36 & 2.1 & 14.0 & 7.0 & 46.7 \\
\hline
\end{tabular}

*Values from reference ${ }^{15}$

they exhibited little influence from geometric discontinuities (Figures 8 and 9).

For a better agreement on the characteristic distances $d_{0}$ and $a_{0}$, a percentage of reference of these distances regarding the liquid width of the plate " $\eta$ " (region of performance of stress concentration) is determined. The liquid width of the plate " $\eta$ " is determined by Equation 7, being $W$ the width of the largest section of area of the specimens $(36 \mathrm{~mm})$ and $R$ the hole and notch radius $(3 \mathrm{~mm})^{17}$ :

$$
\eta=\frac{W}{2}-R
$$

The values of the characteristic distances for both criteria, as well as the percentage differences in relation to " $\eta$ ", are listed in Table 5.

The semi-empirical values of the characteristic distances for $\mathbf{L} 1$ and $\mathbf{L} 2$ showed that the use of the simplified value of $K$, that is, determined solely in relation to the geometry, exhibits good agreement, mainly regarding the percentage of the stress concentration region only for the PSC theory, for samples with a central hole or lateral notches. With respect to the ASC theory, the characteristic distances did not show good agreement, since in all other specimens the value of $a_{0}$ was very similar to that of the region furthest from the boundary of the hole or the center of the specimen (for lateral notch specimens), regions in which stress concentration is minimized, irrespective of the nature of the material and type of geometric discontinuity. $\eta$ values greater than $100 \%$ (L1H and L1N) mean that the characteristic distance showed a higher value than the width of the samples, that is, a point outside the test specimen, which, once again, corroborates the non-validation of the ASC theory.

The use of geometric $\mathrm{K}$ and $R S$ values greater than or equal to 0.9 (L1H, L1N and $\mathbf{L 2 H}$ ) results in non-validated characteristic distance $a_{0}$. When the $R S$ value is near 1.0, the fracture stress of the plate with no discontinuity is close to that of the plate with discontinuity, that is, the influence of stress concentration is minimized, resulting in non-conformity with failure theories, especially the ASC.

Comparison of the values found for L1 and L2 with those reported in the literature $\left(R S=0.7, d_{0}=1.85 \mathrm{~mm}\right.$ and $\left.a_{0}=5.75 \mathrm{~mm}\right)^{1}$ for isotropic $\left(R S=0.82, d_{0}=3.1 \mathrm{~mm}\right.$ and $\left.a_{0}=12.2 \mathrm{~mm}\right)^{19}$ and anisotropic laminates reinforced with glass fibers shows that only the PSC theory exhibited good agreement.

\subsection{Comparative Studies - SEM analysis.}

With the aiming of validated the results microscopic analysis of the final fracture is observed in Figure 12 for all conditions studied.

For L1U and L2U specimens the transverse microcracking of the matrix was observed, as well as glass fiber pull-out. This phenomenon is due to fiber/matrix debonding caused by the propagation of microcracking at the interface ${ }^{6,7}$. Adhesive fractures were also observed at the fiber/matrix interface and cohesive fracture in the matrix. In relation to the $\mathbf{L 1 H}$, L2H, L1N and L2N specimens the geometric discontinuity presence did not significantly modify the final fracture, since microcracks, adhesive and cohesive fractures were found.

For all specimens in the final fracture section, the total rupture of the jute fibers is observed, that is, without fiber pull-out. This phenomenon can be explained by the fact that the fiber tensile strength is less than the tensile strength of the fiber/matrix interface.

The main difference found in the fracture modes was the fact that the specimens with the presence of geometric discontinuity have the localized damage in the stress concentrations region, close to the hole and notch, remaining the specimens without the presence of notable damage in the regions distant from the final fracture.

\section{Conclusions}

With respect to residual strength, both configurations showed a negative influence of a hole and lateral notch. For configuration $\mathbf{L 1}$, the influence of the hole was slightly higher $(2.63 \%)$ than that of the lateral notch. For configuration L2, on the other hand, the greater influence was observed for the lateral notch, almost $11 \%$.

Laminate L1 showed less load support loss than that of laminate $\mathbf{L} \mathbf{2}$, regardless of the type of geometric discontinuity, 31\% L1U higher than L2U, 36\% L1H higher than $\mathbf{L 2 H}$ and $44 \% \mathbf{L 1 N}$ higher than $\mathbf{L} 2 \mathbf{N}$, with respect to tensile strength. These results exhibit coherence with the 


\section{Laminate L1}

\section{Laminate L2}
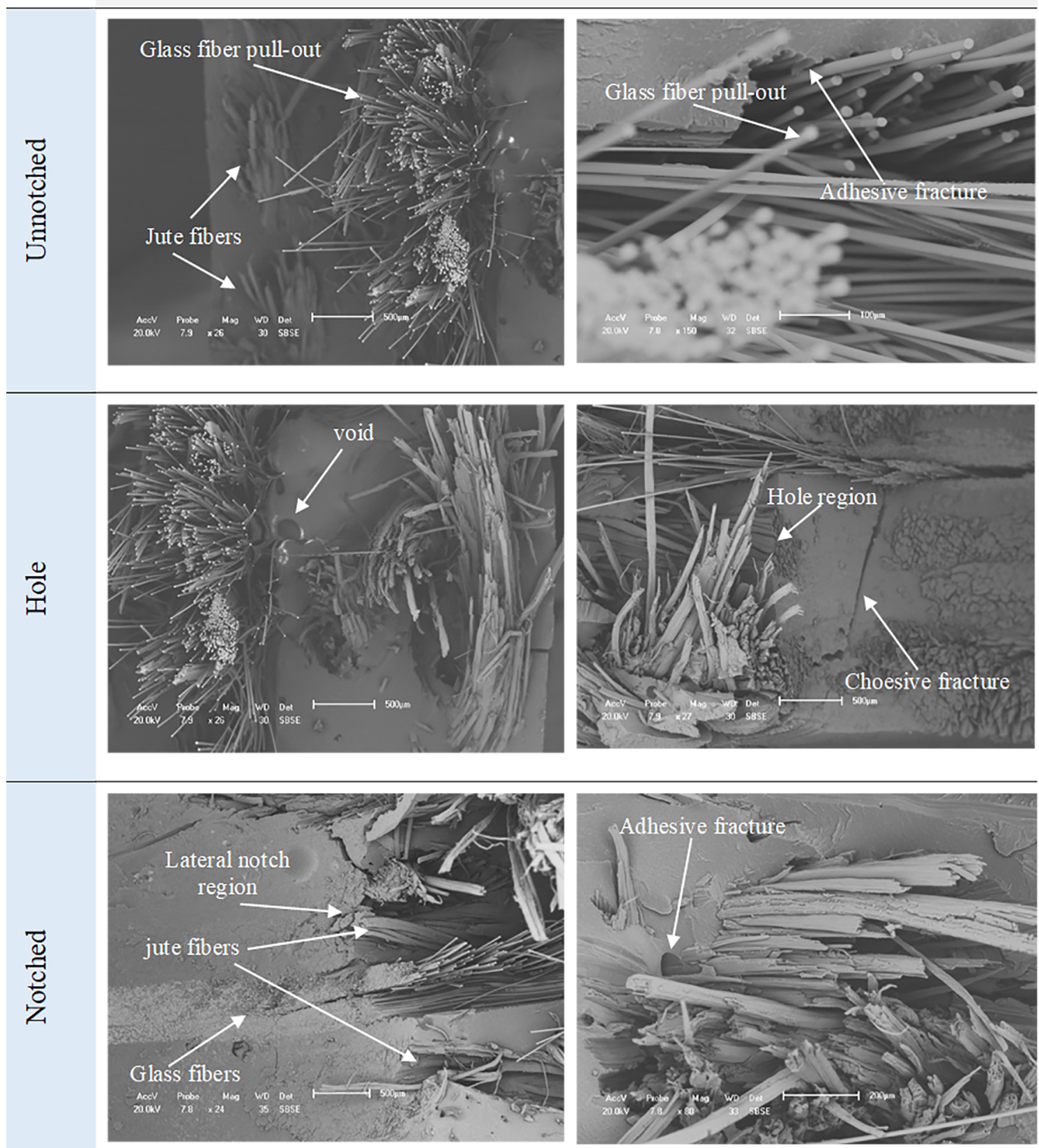

Figure 12. SEM analysis - Composite laminates $\mathbf{L 1}$ and $\mathbf{L 2 .}$

greatest $d_{0}$ distances, showing a certain dispersion in the stress concentration region. Shearing in the outer layers of laminate $\mathbf{L} 1$ may explain this behavior, since studies show that placing fibers at $\pm \mathbf{4 5 ^ { \circ }}$ in the presence of a central hole causes greater residual strength ${ }^{1}$.

Residual modulus shows higher sensitivity to discontinuity of laminate L1, 0.62 and 0.86 for hole and lateral notches respectively. For laminate $\mathbf{L 2}$ ( $R M$ next to 0.92 ), on the other hand, the margins of dispersion demonstrate that there was no influence from discontinuity (both hole and lateral notches) on the longitudinal Young's modulus.

The mechanism of final damage of the composites studied showed the same fracture characterisitcs, that is, LGM (Lateral - gage - middle), regardless of type of configuration 
or geometric discontinuity. One damage characteristic, glass fiber pull-out, cohesive and adhesive fractures were also obtained for all conditions studied.

With respect to the semi-empirical distances found in both failure criteria, when using $K$ (2.36 and 2.58) determined solely in relation to the geometry, of the specimens, good agreement was found only for the PSC theory, since the highest value of $d_{0}$ was $5 \mathrm{~mm}$.

\section{Acknowledgments}

This study was supported by CNPq through scholarship.

\section{References}

1. Tinô SRL, de Aquino EMF. Notched GFRP: anisotropy, residual strength, and fracture characteristics. Journal of Reinforced Plastics and Composites. 2012;31(1):29-40.

2. Liao K, Schultheisz CR, Hunston DL, Brinson LC. Long-term durability fiber-reiforced polymer-matrix composite materials for infrastructure application: a review. Journal of Advanced Materials. 1998;30(4):3-40.

3. Herakovich CT. Mechanics of Fibrous Composites. New York: Wiley; 1997.

4. Ramesh M, Palanikumar K, Hemachandra Reddy K. Mechanical property evaluation of sisal-jute-glass fiber reinforced polyester composites. Composites Part B: Engineering. 2013;48:1-9.

5. Zakriya M, Ramakrishnan G, Gobi N, Palaniswamy NK, Srinivasan J. Jute-reinforced non-woven composites as a thermal insulator and sound absorber - A review. Journal of Reinforced Plastics and Composites. 2016;36(3):206-213.

6. Silva RV, Aquino EMF. Curaua Fiber: A New Alternative to Polymeric Composites. Journal of Reinforced Plastics and Composites. 2008;27(1):103-112.

7. Silva RV, Aquino EMF, Rodrigues LPS, Barros ARF. Curaua/ Glass Hybrid Composite: The Effect of Water Aging on the Mechanical Properties. Journal of Reinforced Plastics and Composites.2009;28(15):1857-1868.

8. L Uma Devi, Bhagawan SS, Thomas S. Dynamic mechanical analysis of pineapple leaf/glass hybrid fiber reinforced polyester composites. Polymer Composites. 2010;31(6):956-965.

9. Saw SK, Sarkhel G, Choudhury A. Effect of layering pattern on the physical, mechanical, and thermal properties of jute/ bagasse hybrid fiber-reinforced epoxy novolac composites. Polymer Composites. 2012;33(10):1824-1831.

10. Zainudin ES, Yan LH, Haniffah WH, Jawaid M, Alothman OY. Effect of coir fiber loading on mechanical and morphological properties of oil palm fibers reinforced polypropylene composites. Polymer Composites. 2014;35(7):1418-1425.

11. Shigley JE, Mischke CR. Mechanical Engineering Design. New York: McGraw-Hill; 2002.

12. Shin CS, Wang CM. An Improved Cohesive Zone Model for Residual Notched Strength Prediction of Composite Laminates with Different Orthotropic Lay-Ups. Journal of Composites Materials. 2004;38(9):713-736.
13. Hallett SR, Green BG, Jiang WG, Wisnom WR. An experimental and numerical investigation into the damage mechanisms in notched composites. Composites Part A: Applied Science and Manufacturing. 2009;40(5):613-624.

14. Mollenhauer D, Iarve EV, Kim R, Langley B. Examination of ply cracking in composite laminates with open holes: A moiré interferometric and numerical study. Composites Part A: Applied Science and Manufacturing. 2006;37(2):282-294.

15. Lau KT, Hung PY, Zhu MH, Hui D. Properties of natural fibre composites for structural engineering applications. Composites Part B: Engineering. 2018;136(1):222-233.

16. ASTM International. ASTM D5766 / D5766M-07 - Standard Test Method for Open Hole Tensile Strength of Polymer Matrix Composite Laminates. West Conshohocken: ASTM International; 2007.

17. ASTM International. ASTM D3039 / D3039M-08 - Standard Test Method for Tensile Properties of Polymer Matrix Composite Materials. West Conshohocken: ASTM International; 2008.

18. ASTM International. ASTM D792-08 - Standard Test Method for Density and Specific Gravity (Relative Density) of Plastics by Displacement. West Conshohocken: ASTM International; 2008.

19. Tinô SRL, Fontes RS, de Aquino EMF. Theories of failure average stress criterion and point stress criterion in notched fiber-reinforced plastic. Journal of Composites Materials. 2014;48(21):2669-2676.

20. Vicente MA, Mínguez J, Martínez JA, González DC. HighPerformance Concrete and Fiber-Reinforced High-Performance Concrete under Fatigue Efforts. In: Ylmaz S, ed. High Performance Concrete Technology and Applications. London: IntechOpen; 2016.

21. Aquino EMF, Sarmento LPS, Oliveira W, Silva RV. Moisture Effect on Degradation of Jute/Glass Hybrid Composites. Journal of Reinforced Plastics and Composites. 2007;26(2):219-233.

22. Freire Jr RCS, de Aquino EMF. Fatigue damage mechanism and failure prevention in fiberglass reinforced plastic. Materials Research. 2005;8(1):45-49.

23. Lautenschläger MI, Mayer L, Gebauer J, Weidenmann KA, Henning F, Elsner P. Comparison of filler-dependent mechanical properties of jute fiber reinforced sheet and bulk molding compound. Composites Structure.2018;203:960-967. DOI: http://dx.doi.org/10.1016/j.compstruct.2017.09.100

24. Johnson S, Kang L, Akil HM. Mechanical behavior of jute hybrid bio-composites. Composites Part B: Engineering. 2016;91:83-93.

25. Hufner DR, Accorsi ML. A progressive failure theory for woven polymer-based composites subjected to dynamic loading. Composite Structures. 2009;89(2):177-185.

26. Awerbuch J, Madhukar MS. Notched Strength of Composite Laminates: Predictions and Experiments - A Review. Journal of Reinforced Plastics and Composites. 1985;4(1):3-159.

27. Nuismer RJ, Whitney JM. Uniaxial Failure of Composite Laminates Containing Stress Concentration. In: Fracture Mechanics of Composites. ASTM STP 593. Philadelphia: ASTM; 1975. p. 117-142. 